\title{
A migração haitiana e a construção de seus "Nortes": Brasil um "Norte" alternativo e temporário
}

\author{
Haitian migration and the construction of its "Nortes": \\ Brazil an alternative and temporary "North"
}

\author{
Kassoum Dieme \\ Tânia Tonhati \\ Lorena Pereda
}

\section{RESUMO}

Desde 2010, o Brasil vivencia as migrações internacionais com maior intensidade e complexidade. Uma das mais expressivas mudanças foi à chegada dos novos fluxos migratórios, com destaque para os haitianos. A imigração haitiana no Brasil tem se consolidado e o presente estudo procurou entender: qual é o local que o Brasil ocupa nos projetos migratórios dos haitianos? Para responder a essa pergunta contamos com os dados da pesquisa Imigração e crise econômica: as táticas migratórias de retorno e circularidade dos haitianos ${ }^{*}$.O trabalho de campo foi realizado no Brasil e Haiti, entre 2018 e 2019. Os resultados encontrados foram que o Brasil é visto frequentemente, nos projetos migratórios dos haitianos, como um "Norte alternativo e temporário”, onde é possível acumular capitais de mobilidade, acadêmico e econômico e, assim, expandir os horizontes de circularidade migratória.

Palavras-chave: Migração haitiana; Brasil; projetos migratórios.

\footnotetext{
* Esse estudo foi realizado pelo Laboratório de Estudos sobre Migrações Internacionais (LAEMI) da Universidade de Brasília (UnB), em conjunto com a Universidade Federal do Paraná (UFPR), com o apoio da Fundação de Apoio à Pesquisa do Distrito Federal (FAP-DF). ** autores
} 


\begin{abstract}
Since 2010, Brazil has experienced international migration with greater intensity and complexity. One of the most significant changes faced by the country was the arrival of new migratory flows, especially from Haiti. The Haitian immigration in Brazil has been consolidated and the present study aims to understand: which role Brazil plays in the migratory projects of Haitians? To answer this question, we rely on data from the research named: Immigration and economic crisis: the migratory tactics of return and circularity of Haitians. The fieldwork was carried out in Brazil and Haiti, between 2018 and 2019. The results found were that Brazil is seen frequently reported as an "Alternative and Temporary North", where it is possible to accumulate capital of mobility, education and economic, which allow them expanding their migratory circularity's horizons.
\end{abstract}

Keywords: Haitian Migration; Brazil; migratory projects

\title{
Introdução
}

De 2010 a 2019, a sociedade brasileira passou por transformações no âmbito das migrações internacionais. Uma das mais expressivas foi à chegada de novos fluxos migratórios e a alteração do perfil migratório do país. Considerado país de imigração, o Brasil recebeu majoritariamente europeus até a primeira metade do século XX (SEYFERTH, 2002; COGO e BADET, 2013). Entre o final dos anos 1940 até o início da década de 1980, o Brasil vivenciou e participou pouco dos movimentos migratórios (PATARRA, 2012). Depois do encerramento do período de ditatura militar (1964-1985), que limitava a chegada de imigrantes e mesmo a saída dos brasileiros, o país voltou a fazer parte da dinâmica migratória. Desta vez através da emigração dos brasileiros para os países do chamado Norte Global, tais como os Estados Unidos, Canadá e países europeus (MARGOLIS, 2013; SOLÉ, ET. AL. 2011; TONHATI, 2019).

A partir de 2010, observou-se, no entanto, um crescimento da população imigrante proveniente de países do Sul Global, fazendo com que, de forma pouco expectável, a população imigrante mais representativa no Brasil torna-se proveniente do Haiti (HANDERSON, 2015). Como demonstrou Telemaque (2012), a imigração haitiana para o Brasil começou antes de 2010, porém, é como advento do terremoto em janeiro daquele ano, que se nota saídas mais expressivas de haitianos, das regiões mais atingidas para outras e para fora do país, inclusive para o Brasil (GODOY, 2011; BERSANI, 2015). 
Diferentemente da República Dominicana, o Brasil não era um destino usual da migração haitiana. Autores como Godoy (2011), Fernandes e Castro (2014), Baptiste (2015) e Handerson (2015) demonstraram como o Brasil entrou na rota da migração haitiana. Para esse último, o país não foi o destino procurado pelos primeiros haitianos que chegaram após o terremoto em 2010. O destino desses era a Guiana Francesa e, posteriormente, a França metropolitana. No entanto, a Guiana Francesa fechou a fronteira para os haitianos e passou a impor diversas restrições. Tal circunstância fez com que dezenas de haitianos ficassem em território brasileiro, dando início à criação das redes migratórias dos haitianos no país. A partir de então, o número de haitianos adentrando o Brasil pela fronteira Norte (Acre e Amazonas)aumentou gradativamente.

Estudos como de Dieme (2016), Handerson (2015), Tonhati et al. (2016) relataram que o Brasil foi gradualmente se tornando o destino de milhares de haitianos. Como forma de organizar e melhor gerir essa migração o Conselho Nacional de Imigração (CNIg) acionou a RN (Resolução Normativa) n $\mathrm{n}^{\circ} 27 \mathrm{e}$ criou a $\mathrm{RN} \mathrm{n}^{\circ} 97^{1}$. A RN n ${ }^{\circ} 27$ atendeu aos cidadãos haitianos, que estavam entrando sem vistos no país solicitando refúgio. A resolução $\mathrm{n}^{\circ} 97$ permitiu ao governo brasileiro conceder visto permanente, de cinco anos, exclusivamente aos nacionais do Haiti por razões humanitárias, o que na prática regularizou a situação migratória desse coletivo no Brasil.

$\mathrm{O}$ ano em que começou este fluxo, assim como nos subsequentes,o Brasil estava em um momento de crescimento econômico, enquanto a crise econômica afetava boa parte do mundo desde 2008 (PATARRA, 2012). Esta prosperidade, no entanto,começou a sofrerum declínio, que, de acordo com Oliveira (2016), se acentuou a partir de 2015. Ele sublinha que a crise econômica "se instalou no país com mais vigor no ano de 2015, chegando a reduzir os postos de trabalho para nacionais [...]” (OLIVEIRA, 2016, p. 60). Dieme $(2016,2019)$ observou que a partir de 2015, o processo migratório dos haitianos no Brasil entrou em um novo momento. Ao mesmo tempo em que continuavam chegando imigrantes haitianos tambémocorreram (re)migra-

1 Esta Resolução Normativa do CNIg - publicada no Diário Oficial da União - Seção 1 № 10 de 13 de janeiro de 2012 - previu em seu Art. $1^{\circ}$ a possibilidade de conceder visto permanente de 5 anos exclusivamente ao nacional de Haiti por razões humanitárias. Estas são as "resultantes do agravamento das condições de vida da população haitiana em decorrência do terremoto ocorrido naquele país em 12 de janeiro de 2010” (DIEME, 2016, p. 237). 
ções destes para outros países tanto da América do $\mathrm{Sul}^{2}$, como para outros destinos, além de movimentos de retorno.

Os fluxos simultâneos de entrada e de saída dos imigrantes haitianos do Brasil, nos remeteu ao estudo de Maria Ioannis Baganha (2002). Essa autora pesquisou a migração portuguesa e constatou que Portugal era uma "anomalia teórica” para os estudos migratórios. Esse caráter anómalo das migrações significava que o país "importa” e "exporta” migrantes com perfis semelhantes simultaneamente. Nesse sentido, Portugal segundo a autora, seria um "laboratório fascinante" de uma complexa combinação de características sociais paradigmaticamente opostas, que o posicionava em uma situação singular em termos dos processos migratórios.

Para Baganha (2002), dentro das dinâmicas migratórias, Portugal se consolidou desde a década de 1990 como sendo uma "placa giratória" (ibidem: 147), redistribuindo a mão de obra migrante pela Europa, tanto portuguesa, quanto brasileira e/ou africana. Como ela argumentou, é pouco provável que "Portugal deixe de ser o Sul para a Europa e o Norte para a África" (BAGANHA, 2002: 153), ou seja, o país atraía imigrantes de países do Sul Global, ao mesmo tempo, que seus nacionais e mesmo os imigrantes residentes nele,(re) migram para países mais ricos do Norte da Europa. Em face do caráter instigante da argumentação de Baganha (2002) e devido aos achados da nossaprópria pesquisa com os imigrantes haitianos no Brasil, nós nos propomos a analisar, se o Brasil na década de 2010-2019, tornou-se uma “placa giratória” na América do Sul,diante da migração haitiana. Esse artigo, portanto, busca identificar o lugar queo Brasil ocupa na dinâmica migratória do coletivo haitiano.

Este trabalho foi dividido em cincoseções, sendo essa introdução a primeira delas. A segunda faz uma breve revisão da literatura existente, dialogando com os principais autores que debatem sobre a migração haitiana no Brasil. Nessa seção realizamos uma discussão histórico-teórica. Na terceira parte apresentamos a metodologia adotada pela pesquisa. E, finalmente, na quarta e quinta partes, discorremos sobre os resultados da pesquisa e concluímos o artigo trazendo algumas ponderações sobre os nossos achados.

2 Para mais informações ver Cf. Folha de São Paulo. https:/www1.folha.uol.com.br/ cotidiano/2016/05/1768958-para-fugir-da-crise-haitianos-trocam-o-brasil-pelo-chile.shtml 


\section{Fatores histórico-teóricos que influenciaram a migração haitiana para o Brasil}

No que tange à imigração do Sul Global, os haitianos ocupam um lugar de destaque no Brasil.Apresentaremos, primeiramente, alguns dos fatores que levaram à emigração dos haitianos para o Brasil, posteriormente, iremos elencar alguns dos fatores que colocaram o Brasil na rota migratória dos cidadãos caribenhos em tela. De modo geral, a análise das migrações internacionais demanda não só um olhar diacrônico, mas também sincrônico. Sayad (1998) assinala que a migração tem uma "dupla dimensão":a "cronológica”, isto é, as saídas precedem as chegadas, e a "epistemológica”, ou seja, a chamada imigração aqui é para outra sociedade umaemigração.

Dentre os fatores que levam à saída dos haitianos do seu país ao longo da história,os estudos citamas questões conjunturaise estruturais. Partindo de alguns estudos recentes é possível afirmar que há uma estreita relação entre a história do Haiti e os movimentos mundiais de colonização, imperialismo, neoliberalismo e ocupações (BAPTISTE, 2015; HANDERSON, 2015; SEGUY, 2014; TELEMAQUE, 2012). De igual modo, cabe abordar a emigração haitiana considerando os contextos nacional e global.

Assim, é pertinente analisar a migração em questão para o Brasil considerando fatores macro-estruturais. É o que ocorre, por exemplo,nas análises dos problemas políticos e econômicos provocados pela herança colonial e pelo neocolonialismono Haiti (DIEME, 2016; THOMAZ, 2010). Sabe-se queo Haiti passou por instabilidades cujas causas profundas são o legado da colonização e de suas novas formas de operar (SEGUY, 2014). Algumas destas serviram de justificativas para intervenções unilaterais ou internacionais que teriam como objetivo assegurar a estabilidade no país. De 2004 a 2017, a MINUSTAH $^{3}$, uma Missão de Paz da Organização das Nações Unidas atuou no Haiti, tendo sido antecedida por outras. De acordo com Thomaz (2010) desde o começo da década 1990, o Haiti está inteiramente sob "tutela das grandes organizações internacionais” (p. 24). Para Mamed (2018, p. 68) o terremoto em 12 de janeiro de 2010 no Haiti “mobilizou a 'Internacional Comunitária' e as bases para a 'recolonização’ do país, na qual a atuação brasileira,

3 Esta missão foi estabelecida em 2004 pelo Conselho de Segurança das Nações Unidas "sob o nome de Mission des Nations Unies pour la Stabilisation en Hä̈ti.” (DIEME, 2017, p. 27). 
desde 2004, como líder [do braço militar] da [...] Minustah, já demonstrava integrar o ambicioso projeto subimperialista" ${ }^{4}$.

Embora insuficiente para explicar a emigração haitiana para o Brasil,a colonização, as invasões e mesmo a Missão de Paz foram fatores considerados relevantes para analisar este fenômeno. A esse respeito, Baeninger e Peres (2017) colocaram que,

[...] o Haiti se constrói historicamente com a presença econômica e militar estrangeira (CASTOR, 2008; SEGUY, 2014), com o domínio colonial no século XVIII (JAMES, 2010), com o controle político e militar dos Estados Unidos no século XX (CASTOR, 1971) e com a presença brasileira no início do século XXI (LUCE, 2011; MAGALHÃES, 2014). Assim, seus processos emigratórios vinculam-se também a tais presenças militares em território haitiano (p. 123).

A colonização e as ocupaçõesaparecem na literatura sobre as migrações como fatores geradores, acurto, médio ou longo prazo, das contracorrentes migratórias. Por exemplo, Portugal recebeimigrantes das suas ex-colônias naÁfrica, sobretudo, angolanos, cabo-verdianos, da América do Sul, cidadãos brasileiros (BAGANHA, 2002; NOLASCO e RIBEIRO, 2018). A França é o destino de magrebinos, africanos francófonos, indochineses e haitianos (DUROUX, 2011; HANDERSON, 2015).A relação colonização, ocupação e migração levou autores como Fernandes e Castro (2014), Handerson (2015), Seguy, (2014) e Baeninger e Peres (2017) a correlacionar apresença militar brasileira no Haiticom a migração desse coletivopara o Brasil.

A essas intervenções e à herança colonial se somam osefeitos daspolíticas macroeconômicas globais e os fechamentos das fronteiras de alguns dos destinos tradicionais da emigração haitiana, como por exemplo,para países do Norte Global, comoEstados Unidos e França. Segundo dados da OCDE/INURED $(2017)^{5}$, em 2015,11,2\% da população haitiana viviam fora do Haiti, sendo que desse número 600 mil estavam nos EUA e 70 mil na França. Esta presença significativa não é necessariamente sinônima de permanência legal, nem de boa acolhida. Em 2018,o jornal espanhol EL PAÍS6 informou que

4 Cabe notar que a relação entre migração internacional e colonização é referida por vários estudos (SEYFERTH, 2002; SEGUY, 2014; HANDERSON, 2015, SAYAD, 1998; SANTOS, 2002; DUMONT, 2019).

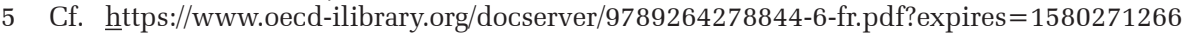
\&id=id\&accname $=$ guest\&checksum $=$ 69DE5E73DF0107A15DE57346F1CE06B1

6 Cf. https://brasil.elpais.com/brasil/2018/01/11/internacional/1515710855_459301.html 
o presidente dos EUA (Donald Trump) retirou os haitianos de um programa que permitia sua residência legal. Tal política restritiva afetou a 59.000 haitianos. Handerson (2016) observou também políticas de restrições à entrada de haitianos em território francês da Guiana após 2010.

Com relação àspolíticas macroeconômicas globais, Galeano (2014) afirma que o Haiti é um "país submisso às ordens do Banco Mundial e do Fundo Monetário, o Haiti havia obedecido suas instruções sem murmúrios” (Cf. DIEME, 2016, p. 67). Essas políticas levariam à instabilidade política e socioeconômica. O que se desdobra, segundo Handerson (2015) em um leque de carências como: a falta de serviços de saúde, de oportunidade de estudo e trabalho.

Importa notar, ainda,como fator que levou à saída de milhares de haitianos para o Brasil, o terremoto de 12 de janeiro de 2010. Esse atingiu de forma particularmente violenta não só a capital haitiana Porto Príncipe - sendo essa a principal cidade e o principal polo de imigração, como afirmado por nossos interlocutores haitianos retornados do Brasil - mas também, de acordo com Thomaz (2010, p. 24), as seguintes cidades: Pétionville, Léogâne, Petit-Goâve, Grand-Goâve e Jacmel. Ou seja, "Porto Príncipe, [...], e seus entornos, área mais densamente habitada” (SEGUY, 2014, p. 24). Descrito como um fenômeno ambiental, seu impacto é analisado por este autor como fruto de natureza devastada desde os tempos coloniais e que não foi, nem depois da catástrofe, objeto de preocupações políticas sérias. Segundo Seguy (2014) e Handerson (2015), o terremoto veio agravar um contexto já marcado pelas carências estruturais. Diante desse agravamento uma das soluções às quais a juventude recorreu foià emigração, socialmente entendida como uma forma de ascensão social (BAPTISTE, 2015, HANDERSON, 2015).

Como apontou Handerson $(2015 ; 2016)$ e Dieme (2016) dois pontos sobressaltam quando buscamos explicar a emigração haitiana para o Brasil. Primeiro,tem que se levar em conta a saturação e a tensão que sofrem os haitianos na vizinha República Dominicana. Segundo, o fechamento das fronteiras e as políticas restritivas dos países como: os Estados Unidos, Canadá ea França. Esses são alguns elementos, adicionados aos outros que mencionamos mais acima, que contribuíram para que os haitianos buscassem um país “alternativo", em que fosse possível atender as necessidades de formação acadêmica, técnica, de trabalho ou emprego e também de segurança.

O Brasil, até meados de 2014, tinha um bom desempenho econômico, e era uma opção interessante no Sul Global, entrando de forma inesperada no- 
horizonte da migração haitiana (PATARRA, 2012; HANDERSON, 2015). Sendo, segundo Dieme (2016), apresentado pelos chamados coiotes como um país onde se poderiatrabalhar e ganhar um salário alto, isto é, como um novo peyi blan ${ }^{7}$. Para Patarra (2012), a vinda dos haitianos se justificava também pela liderança brasileira na América Latina e pela sua avançada legislação sobre refúgio $^{8}$, às quais se somou a criação,em janeiro de 2012 e com base na Resolução Normativa no 97 -o visto humanitário criado exclusivamente para os cidadãos haitianos que almejam vir residir no país.

O visto humanitário para os haitianos foi definido como permanente, tinha validade de cinco anos e sua renovação dependia de comprovação da situação laboral do requerente. Inicialmente foi previsto a emissão de 100 vistos por mês, isto é, 1.200 por ano durante dois anos. No entanto, estas quotas foram retiradas diante do tamanho da demanda e da continuidade de entradas de haitianos no Brasil pela fronteira Norte. O Brasil autorizou, por algum momento, a emissão desse visto em embaixadas do Brasil em São Domingos, Lima, Quito e Panamá, além de Porto Príncipe. Apesar desta medida, que buscava pôr um fim na entrada de migrantes haitianos sem visto no país, envolvendo indiretamente países terceiros tal como o Equador e o Peru, na busca dessa solução, observou-se que pelo menos até 2015, a fronteira terrestre no Norte ainda servia de lugar de entrada para os haitianos (DIEME, 2016; TONHATI, 2016). Extinto o visto permanente criado pela $\mathrm{RN} \mathrm{n}^{\circ} 97 \mathrm{em}$ outubro de 2017, foi criado outro, temporário, em 6 de abril de 2018 pela Portaria Interministerial $\mathrm{n}^{\mathrm{o}} 10$, e também reservado aos mesmos cidadãos, além de apátridas residentes no Haiti por razões humanitárias ${ }^{9}$.

O Conselho Nacional de Imigração (CNIg) concedeu 708 autorizações de residência a haitianos em 2011. Em 2012 foram 4.825 concessões para esta

7 "Peyi blan é umpaís estrangeiro, mas, geralmente, aqueles considerados como tendo um bomdesenvolvimento socioeconômico. No imaginário haitiano, é considerado comoum paraíso, onde há neve, faz frio, ganha muito dinheiro, enfim, onde há bem-estar social, uma realidade totalmente diferente do Haiti” (Handerson, 2015, p. 28).

8 Para Barreto (2010), a Lei No 9474 de 22 de julho de 1997 é considerada aberta, avançada e respeitosa pela ONU (Cf. DIEME, 2016, p. 148) pois, entre outras coisas, possibilita a obtenção de documento provisório para solicitante de refúgio, que pode inclusive trabalhar enquanto aguarda a decisão do CONARE (Comitê Nacional para Refugiados), ao contrário do que ocorre países como a França ou Estados Unidos, por exemplo.

9 Segundo o Ministério das Relações Exteriores: "Esse visto será emitido exclusivamente pela Embaixada do Brasil em Porto Príncipe e permitirá a concessão de residência temporária de dois anos no Brasil, passível de transformação em residência por prazo indeterminado ao final desse período".Para saber mais ver: < http://www.itamaraty.gov.br/pt-BR/notas-aimprensa/18622-visto-humanitario-para-haitianos. 
nacionalidade. Estes números diminuíam para 2.069 em 2013 e para 1.890 em 2014. No entanto, atingiram 34.773 em 2015. Segundo Tonhati (2016), tal aumento ocorreu em razão de que de 2010 a 2015, uma tática migratória utilizada pelos haitianos para dar entrada, permanecer e trabalhar (com carteira de trabalho) no Brasil foi solicitar refúgio ao governo brasileiro. Porém, muitos desses imigrantes não cumpriam os requisitos do estatuto do refúgio. Desde modo, no ano de 2015, o Ministério do Trabalho e da Justiça assinaram um ato conjunto com o objetivo de regularizar a situação migratória dos haitianos que solicitaram refúgio, mas não se enquadravam na condição de refugiados. O CNIg concedeu aos nacionais do Haiti o visto permanente por razões humanitárias. Já a ausência de autorizações de residência a haitianos em 2016 está ligada ao redirecionamento dos vistos aos haitianos para o Ministério da Justiça,a redução das entradas terrestres e à regularização migratória definitiva. Em 2017 e 2018 foram respectivamente 1.244 e 364 solicitações de autorização de residência pedidas ao CNIg (DIEME et al. 2019). Somando 45.873 concessões de residência por razões humanitárias a haitianos que já se encontravam no Brasil pelo CNIg de 2011 a 2018. De acordo com Oliveira (2018):

[...] a partir de 2010, os haitianos (101,9 mil) aparecem como primeira nacionalidade em termos de regularização no período, acompanhados na sequência entre os principais países por: bolivianos (79,4 mil), colombianos (48,2 mil), argentinos (40,9 mil) e norte-americanos (39,9 mil), o que demonstra claramente o deslocamento para o Hemisfério Sul entre as origens mais determinantes (OLIVEIRA, 2018, p. 61).

Em suma, como demonstrado pela literatura existente, à migração haitiana para o Brasil combina elementos sócios históricos, estruturais e ambientais. Tais fatos levaram esse país a apresentar alto déficit de desenvolvimento social e econômico, entre outros, o que proporcionou a emigração de seus cidadãos para outros países, criando uma cultura de migração (HANDERSON, 2015). Os autores, que buscaram um olhar particular para a imigração haitiana no Brasil, revelaram que essa tem um crescimento significativo a partir de 2010, após o terremoto que devastou o Haiti. Como vimos, o Brasil entra na rota da migração haitiana como uma alternativa, já que países como Estados Unidos, França, Canadá criaram políticas restritivas. Nesse processo, o Brasil é construído, tal como demostrado nas próximas seções, como um “Norte Global alternativo” e “temporário” para a migração haitiana. 


\section{Metodologia}

O presente artigo teve como base o projeto de pesquisa: Imigração e crise econômica: as táticas migratórias de retorno e circularidade dos haitianos, desenvolvido pelo Laboratório de Estudos sobre Migrações Internacionais (LAEMI) da Universidade de Brasília (UnB), em parceria com a Universidade Federal do Paraná (UFPR), com o apoio da Fundação de Apoio à Pesquisa do Distrito Federal (FAP-DF). A pesquisa foi multisituada (Marcus, 1995) e realizada no Brasil, no Distrito Federal (Brasília, São Sebastião, Paranoá, Itapoá, Plano Piloto e Guará II) e em Paraná (Curitiba), e no Haiti, na capital Porto Príncipe ${ }^{10}$ e em outras cidades: Jacmel, Mare Rouge, Anse-Rouge e Saint-Marc.

A pesquisa foi realizada através de entrevistas semi estruturadas e o contato com os participantes se deu em função do critério de heterogeneidade e acessibilidade, recorrendo à técnica da "bola de neve"11 (BALDIN E MUNHOZ, 2011).No Brasil foram entrevistados 45 haitianos, sendo 34 homens e 11 mulheres. No Haiti foram 19 entrevistados retornados do Brasil, sendo 13 homens e 6 mulheres. Além das entrevistas, o estudo realizou grupos focais nas cidades brasileiras. Em Brasília (DF), o grupo focal,com 5 homens e 2 mulheres,foi realizado em 01 de maio de 2018. Em Curitiba (Paraná), o grupo focal, composto por 14 homens e 6 mulheres, foi realizado em 4 de agosto deste ano.

\section{Brasil, um "Norte Global alternativo": redes e formação acadêmica}

As redes no contexto das migrações internacionais são entendidas por Pedone (2004) como:

[...] estrategias puestas en marcha por los propios migrantes ante el juego de poderes nacionales e internacionales y para interpretar la per-

$10 \mathrm{Na}$ capital foram realizadas entrevistas em Pétion Ville, Jacmel, Croix de Bouquets, Carrefour e Delmas.

11 A técnica "Bola de Neve" é uma forma de amostra não probabilística utilizada em pesquisas sociais, na qual os participantes iniciais do estudo indicam novos participantes que, por sua vez, indicam novos participantes, até que seja alcançado o objetivo proposto ou o ponto de saturação da pesquisa. O IMDH, estudantes, ex-estudantes ou trabalhadores haitianos residentes no Brasil ou no Haiti, bem como o Centro Cultural Brasil-Haiti ajudaram nesse sentido. 
manente redefinición de las relaciones de solidaridad y de conflicto, en distintos niveles (Cf. PEREDA, 2019, p. 25)12.

Nossa pesquisa de campo revelou que a imigração haitiana para o Brasil contou com a centralidade das redes migratórias envolvendo instituições religiosas ou laicas, familiares e de amizade, legais ou "ilegais" mobilizadas pelos imigrantes e/ou seus familiares. Entre os nossos entrevistados, muitos contaram ter recebido apoio de redes religiosas para poder ir morar e estudar no Brasil. Uma participante informouter sido apoiada pela mãe e viajado com a ajuda de atravessadores, e outro entrevistado contou com a ajuda de um amigo migrante retornado.

Frano, um entrevistado retornado do Brasil para o Haiticita uma das razões que o motivou a vir estudar no Brasil:

Meu melhor amigo naquele tempo, já tinha estudado no Brasil, [...], ele foi assassinado no dia do terremoto em 2010. Ele era professor na faculdade, ele fez seu mestrado e doutorado na UFPE em Pernambuco. Então quando eu conversei com ele sobre o meu projeto, ele me respondeu assim: "Eu acho, que a minha faculdade é o lugar ideal para você desenvolver essa pesquisa porque tem um centro de pesquisa sobre movimentos sociais (Frano, Porto Príncipe - Haiti).

Já outro entrevistado, Federico, morador de Brasília, quando perguntado sobre as facilidades identificadas na chegada ao Brasil falou:

A facilidade para vir, porque a gente já tinha família aqui né, [...], a gente vem direto na casa da família, a gente já tem pessoa que sabe, que fala a língua natal né, a gente morava juntos lá no Haiti e viemos morar aqui no Brasil juntos, pramim é uma facilidade, tem gente que vem em um país sem saber a língua né, só vem para cá para conhecer e não sabe onde vai morar, pra mim, que tem mãe e irmã, é uma facilidade.(Federico, Brasília - Brasil).

Além dos estudos, o entrevistado Lysno afirmou que a facilidade para a obtenção do visto e a presença do primo, que já morava no país, foram fatores determinantes para sua vinda ao Brasil.

12 Tradução nossa: "estratégias implementadas pelos próprios imigrantes frente ao jogo de poderes nacionais e internacionaise para interpretar a permanente redefinição das relações de solidariedade e de conflito, em distintos níveis" 
No momento que eu encontrei esse visto, eu não tive tempo de terminar meu TCC, mas eu vim, e eu tinha o meu primo, que estava morando aqui em Brasília. Eu vim para cá, [...] a gente morou 1 ano junto, depois eu saí e fui morar com meu irmão só. (Lysno, Brasília - Brasil).

Para além das redes de contato de familiares e amigos, a pesquisa encontrou que instituições religiosas foram fundamentais para a vinda de alguns haitianos para o Brasil. Nelive, imigrante retornada disse: Na igreja onde vocês foram, é aquele pastor que entrou em contato com a instituição Izabela Hendrix. É ele que fez tudo, todos os tramites até a obtenção do visto. Ele inclusive viajou conosco. Lenga, Quinjo e Caniesh vieram com o auxílio dessa instituição também.Eles demonstraram satisfação em poder avançar em sua formação no Brasil, argumentando que teriam uma formação de qualidade, a qual seria bem reconhecida, possibilitaria a abertura do mercado de trabalho e ajudaria no desenvolvimento do Haiti.O entrevistado retornado Quinjo disse:

[...] esse programa que eu participei foi um programa no ministério aqui no Haiti que se chama Ministério de visão global do Haiti que teve contato com o reitor da faculdade Izabela Hendrix na época, então deu essa oportunidade de ir pra lá para estudar. Mas, o objetivo foi ir lá para estudar e depois voltar o país para ajudar na questão do conhecimento que a gente conseguiu lá, volta pra trabalhar para ajudar o país, foi isso o objetivo. (Quinjo, Porto Príncipe - Haiti).

Para esse subconjunto de imigrantes retornados, bem como para Toussaint, Frano, Mondieu e Sanité,que vieram para o Brasil em busca de formação educacional e financiados pelo governo brasileiro- o que foi um fator determinantena escolha do Brasil como destino - através de bolsas de estudo de pós-graduação, o país se tornouum “Norte Global alternativo”. Observamos que esses entrevistados colocam o Brasilmais próximo do Norte do que do Sul Global, em termos de status acadêmico que conseguiram atingir. Ao mesmo tempo, a escolha pelo Brasil também se deu por acreditar que esse tinha mais semelhanças com o próprio Haiti, o que o distanciaria do Norte Global. É possível observar esse paradoxo na fala do participante a seguir, caracterizando essa construção de um espaço alternativo:

Porque em 2007 quando eu estava me preparando pra o meu projeto de estudo, eu tive um professor na minha faculdade, ele praticamente 
lutou comigo pra não ir pro Brasil. "Não, mas tem uma bolsa pra Washington, porque é que você prefere o Brasil?” Eu tinha essa oportunidade de ir para Washington, mas aí eu falei: "Não, eu acho que o Brasil é melhor para mim”, "Mas por quê?”. "Eu não conheço o Brasil, mas eu acredito que eu talvez, ou com certeza, é mais fácil eu encontrar algumas realidades mais próximas das realidades haitianas do que num Estado como Washington (Frano, Porto Príncipe - Haiti).

A pesquisa observou, ainda, que para os imigrantes haitianos que vieram para o Brasil com o propósito principal de acumulação e envio de remessas, e, portanto, tinham a atividade laboral como prioridade (mesmo que muitos reportaram desejo em combinar trabalho e formação acadêmica), o Brasil também foi entendido como um "Norte Global alternativo”. Embora o país não lhes ofereça altos salários e apresente grandes desafios na vida laboral, à maioria dos entrevistados avaliou melhor o Brasil que o Haiti, tanto em termos de oportunidades de trabalho como de segurança. É o que relatam os entrevistados a seguir.

É por conta de segurança mesmo, porque quando eu estava lá, ganhava mais né, mas aqui, é mais tranquilo né? (Federico, Brasília Brasil).

O Brasil, portanto, é construído nas narrativas dos nossos participantes como um local "alternativo", que permite a realização, bem ou mal, de seus objetivos centrais: estudar e/ou trabalhar. Ou seja, é possível adquirir renda, formação acadêmica e até mesmo segurança no Brasil. Esses elementos permitiriam a eles alcançar status social perante amigos, familiares e a sociedade no Haiti. É nesse sentido que caberia a apelação de "Norte Global alternativo" para designar o Brasil.

As conversas com nossos interlocutores no Brasil e no Haiti revelaram ainda que as ideias de "temporalidade" e "provisoriedade" são bastante recorrentes nos relatos das suas experiências migratórias, inclusive após o retorno. Nesse sentido, nos perguntamos: Seria o Brasil,para além, de um "Norte Global alternativo”, um "Norte temporário”? 


\section{Brasil: "Norte temporário" e "placa giratória” na construção do projeto migratório dos haitianos}

Os termos "temporário" e "placa giratória”são conceitos relacionados à migração internacional, que remetem não só ao movimento geográfico de pessoas, mas também a suas condições jurídicas, econômicas e/ou sociais. Como já dizia Sayad (1998, p. 45).

[...] a imigração condena-se em engendrar uma situação que parece destiná-la a uma dupla contradição: Não se sabe mais se se trata de um estado provisório que se gosta de prolongar indefinidamente ou, ao contrário, se se trata de um estado mais duradouro, mas que se gosta de viver com um intenso sentimento de provisoriedade (SAYAD, 1998, p. 45).

No âmbito de migração internacional, portanto, o adjetivo "temporário" remete à condição de provisoriedade, objeto de análise em Sayad (1998) que o entendeu como ilusório. Para o autor, o fenômeno migratório gira em torno da ilusão da provisoriedade e têm três "parceiros que são a sociedade de emigração, a sociedade de imigração e os próprios emigrantes/imigrantes, os primeiros envolvidos" (SAYAD, 1998, p.18). Se o Brasil é aqui entendido como um "Norte Global alternativo" para as migrações dos Sul Global, na medida em que exerce sobre eles um elevado poder de atração na última década (20102019), e que nele podem arrumar trabalho, ganhar dinheiro, adquirir formação acadêmica, competências, ter relativamente paz e viver num lugar bom, como sugeriu,de certa forma, Handerson (2015) com a noção de peyi blan, a questão que se coloca agora é seguinte: É a estadia de haitianos no Brasil temporária?

Para responder a esta pergunta, consideramos num primeiro momento as medidas jurídicas tomadas ou acionadas pelo Estado diante da imigração haitiana. Observamos que as resoluções, como foi o caso da $\mathrm{RN} \mathrm{n}^{\circ} 97$ de 12 de janeiro de 2012 e da Portaria Interministerial $n^{0} 10$ de 06 de abril de 2018, bem como a aplicação da $\mathrm{RN} \mathrm{n}^{0} 27$, todos dispositivos legais, remetem explícita ou implicitamente à provisoriedade. O documento interministerial de forma mais evidente e os demais um pouco menos, mesmo quando são considerados como vistos permanentes, demandam renovação periódica a cada dois ou cinco anos.

Em termos econômicos e/ou sociais a provisoriedade da permanência no Brasil foi relatada pelos entrevistados da nossa pesquisa, no sentido das di- 
ficuldades de acender a postos de trabalho com remuneração mais alta, e ainda, as incertezas com relação a permanência no mercado de trabalho, em consequência da crise econômica brasileira. E, até mesmo, a dificuldade de combinar as atividades do trabalho e a ampliação da formação acadêmica. Encontramos diversos relatos que colocaram a estadia no Brasil como sendo passageira. Alguns dos participantes reportaram que tinham planos de deixar o país a médio ou longo prazo e retornar para o Haiti.

[...] Na verdade, fico até o dia que melhorar a segurança de lá, aí eu vou, porque o Haiti,porque lá fica melhor para mim” (Federico, Brasília - Brasil).

[...] eu quero ficar fora do país [Haiti] alguns anos, talvez 10 a 15 anos, não sei, mas depois eu quero voltar também” (Dans, Curitiba - Brasil).

Os chamados países do Norte Global constituem os destinos mais almejados após eventual saída do Brasil. Em seu relato, o entrevistado Enzy, assinalou que pretendia permanecer no Brasil por um tempo determinado.Para ele, a estadia no país se estenderia até que conseguisse ir para os EUA,e depois para o Canadá, onde ele acredita que atingiria uma estabilidade maior.

Pesquisador: Mas você está querendo ir daqui para o Haiti, do Haiti para os EUA e dos EUA para o Canadá?

Enzy: Sim, exatamente. E aí vai ficar mais estável.

O desejo de realizar esse percurso também foi expresso por outra entrevistada, Venala, moradora de Curitiba. Ela afirmou:

Eu quero ir pros Estados Unidos ou Canadá, porque lá no Canadá você estuda melhor. Tenho bastante família também. Visto de estudante tá difícil porque eu sou haitiana e to aqui no Brasil, eu já pedi visto pros EUA, mas eles negaram, porque sabiam que eu não ia voltar, eles negaram, não deixa. Mas [...], eu quero mais Canadá agora, porque dá mais oportunidade pra trabalhar, trabalhar não, estudar. (Venala, Curitiba - Brasil).

A entrevistada Nadecha, disse: Saio do Brasil se for para ir pros Estados Unidos e França também sim, para outro país não (Nadecha, Curitiba Brasil). 
Para além dos Estados Unidos, do Canadá e da França, também apareceu o Chile nos projetos migratórios de circularidade haitiana. Sanité disse:

[...] o foco migratório não é mais o Brasil, agora pouco era o Chile. Acho que agora diminui um pouco, porque começaram a mandar os haitianos de volta pra cá e tudo mais, mas tem muitos haitianos que deixam o Brasil por conta da crise, e foram para o Chile (Sanité, Porto Príncipe, Haiti).

As falas dos nossos entrevistados, que tinham o desejo de (re)migrar saindo do Brasil, mostram que para estes o Brasil se constitui dentro do projeto migratório como um país alternativo e também temporário. Ele é visto como um lugar que permite atingir alguns objetivos como: juntar algum recurso financeiro, obter formação acadêmica, visto. Esses são elementos a serem adquiridos, ou como cunhados por Oliveira e Kulaitis (2017), são capitais de mobilidade, que serão posteriormente utilizados para continuar o projeto migratório.

A presente pesquisa contou com entrevistas com haitianos retornados do Brasil para o Haiti, como reportado na metodologia. Quando consideramos as falas desses interlocutores, vimos que quase todos haviam emigrado para realizar estudos nos seguintes níveis: graduação, especialização ou mestrado. Portanto, migraram já com o propósito de uma estadia temporária. A maioria havia atingido seus objetivos estabelecidos, quando retornaram e relataram que tinham "boas expectativas de emprego" e/ou "retomada do trabalho deixado". Foi o caso de Quinjo, Toussaint e Caniesh. A entrevistada Caniesh quando perguntada sobre a sua experiência migratória e a contribuição dessa para sua mobilidade social e econômico no Haiti, respondeu:

É, eu acho que contribuiu sim, porque eu achei um trabalho porque eu estudei [...] e eu trabalho em projetos aqui no ministério e o ministério é do governo e aí eu acho que contribui assim, porque aqui se você não tem um papel, não vai poder achar um trabalho (Caniesh, Porto príncipe - Haiti).

O Brasil, para muitos desses, foi um "Norte alternativo e temporário" não só por oferecer uma boa formação, mas também pelo nível de desenvolvimento em relação ao Haiti e, sobretudo, pela intenção, compromisso e ato de retornar para Haiti. Muitos dos retornados relataram que após os estudos no 
Brasil conseguiram um emprego satisfatório ou melhores condições laborais no Haiti. Foi o caso do entrevistado Lenga.

Ele [o diretor] tinha dito "poderia ter ficado pra fazer doutorado", eu falei "não, agora vou voltar". E agora sinceramente estou muito satisfeito, o projeto que estou tá ajudando na formação de jovens, técnicos agrícolas, [...], então quer dizer, uma pessoa que queria sair do país para ir pro Brasil, pra Chile pra poder fazer isso, mas ao invés disso pode fazer aqui, porque tem uma empresa[agrícola], isso me deixa satisfeito, sabe? (Lenga, Jacmel, Haiti).

A estadia temporária de imigrantes, que teria o retorno com um desfecho final é, do ponto de vista teórico discutível, pois como demonstraram os trabalhos de Cassarino (2013) e Sayad (2000), o retorno não põe fim à migração,esse faz parte do próprio fenômeno. Cavalcanti e Parella (2013, p. 16) afirmam que"el retorno debe ser conceptualizado desde enfoques que lodefinan como una etapa más del ciclo migratorio, a partir de patrones de circularidad"13.

Tal fato, também apareceu em nosso estudo, seis dos retornados que entrevistamos ainda almejam (re)emigrar para outro país para avançar nos estudos,fazer um curso ou para trabalhar. Eles procuram dar continuidade ao seu projeto de vida através da realização de projetos migratórios. Assim, fomos chegando à conclusão de que o Brasil se constitui para a migração haitiana recente como uma possível "placa giratória”. O país passa a ser um local importante para aquisição de conhecimentos e recursos financeiros para impulsionar e construir a possibilidade de uma nova mobilidade.

A noção de "placa giratória” cunhada por Baganha (2002) está associada às ideias de chegada de imigrantes, de provisoriedade de sua estadia, de qualificação profissional e de emigração dos nacionais e/ou imigrantes para outros destinos. Ela remete também a uma posição classificável como intermediária do território analisado entre o Norte e o Sul Globais. Para se enquadrar como "placa giratória”, o Brasil deve ser considerado como parte da periferia do Norte Global.

13 Tradução nossa: "o retorno deve ser conceituado desde enfoques que o definam como mais uma etapa do ciclo migratório, a partir de padrões de circularidade”. 
Diante do que foi exposto, percebemos que o Brasil recebe imigrantes haitianos, tanto formados e em busca de mais qualificação, quanto com pouca formação profissional ou escolaridade. No caso dos entrevistados, alguns se qualificaram, outros elevaram seu grau de qualificação e outros mantiveram os perfis profissionais. Muitos dos nossos entrevistados almejam (re) emigrar para um país do Norte Global (Estados Unidos e Canadá) em busca de melhores condições laborais e também de formação acadêmica e/ou capacitação profissional. Outros mencionaram a possibilidade de ir para o Chile, ou ainda, pretendem retornar para o Haiti, por um período e repensar possibilidades de outras mobilidades. Nesse sentido, podemos dizer que a migração haitiana complexificou o papel do Brasil no contexto das migrações internacionais. Com relação aos debates teóricos, o Brasil pode ser, portanto, pensado como exercendo a função de uma "placa giratória” para os imigrantes haitianos. O país entrou no circuito dessa migração e é parte da construção do projeto migratório de diversos haitianos.

\section{Considerações finais}

O presente artigo debateu sobre a construção e o local que o Brasil ocupa na migração haitiana. Nosso olhar analítico sobre as entrevistas realizadas revelou que, de modo geral, para os imigrantes haitianos participantes do nosso estudo, tanto para aqueles ainda residentes no Brasil, quanto para os que retornaram para o Haiti, o Brasil é visto como um lugar em que é possível encontrar condições favoráveis para "melhorar de vida". Isto é, atingir importantes objetivos, seja mediante o trabalho e/ou os estudos/cursos. O Brasil, assim, se constitui como um "Norte alternativo".

No entanto, o estudo também reportou que com a experiência de viver no Brasil, este passou a ser entendido, por alguns dos entrevistados, como situado fora do Norte Global. Tal posição torna o país ao mesmo tempo um "Norte alternativo" e "temporário", na medida em que o Norte Global almejado é de difícil acesso e que o Brasil é procurado pelos imigrantes haitianos como um destino atrativo para trabalhar, ter experiências profissionais, formação acadêmica e ampliar o horizonte migratório. Na prática, esta passagem tida como "temporária” nem sempre ocorre como desejada, o que faz com que a provisoriedade da estadia no Brasil possa se alongar por anos. 
Em outros termos, conclui-se que o Brasil atrai tanto haitianos qualificados, quanto aqueles em busca de mais qualificação e oportunidade de trabalho. Assim, o país foi visto como um "Norte alternativo", onde é possível acumular conhecimento, savoir-faire ou capital econômico, e parte dos que aqui adquirem estes capitais deixam o país retornando para o Haiti ou indo para um país do Norte Global ou outro "Norte alternativo". Neste sentido, o Brasil recebe e perde, não na mesma proporção, imigrantes com características semelhantes: sem formação, pouco formados ou altamente qualificados, se tornando uma placa giratória para a migração haitiana.

O caso da migração haitiana no Brasil contribui para ilustrar o lugar que este vem ocupando na migração internacional contemporânea. O país é tanto um "Norte alternativo"como um "Norte temporário" para os imigrantes haitianos. O caso particular do coletivo haitiano permite pensar que é pouco provável que o Brasil deixe de ser um Sul para os Estados Unidos, Canadá e França e um Norte para o Caribe e a América Latina - como diria Baganha (2002).

\section{Referências}

BAENINGER, Rosana e PERES, Roberta. (2017), "Migração de crise: a migração haitiana para o Brasil”. Revista Brasileira de Estudos de População, Belo Horizonte, v.34, n.1, p.119-143.

BAGANHA, Maria Ioannis. (2002), "A cada Sul o seu Norte: dinâmicas migratórias em Portugal”. In: SANTOS, Boaventura de Sousa (org.). A globalização e as ciências sociais. - 2. Ed. - São Paulo. Cortez.

BAPTISTE, Chandeline Jean. (2015), Transição para a vida adulta e migração internacional: ocaso dos jovens haitianos na cidade de São Paulo. Dissertação (Mestrado em demografia). Universidade Estadual de Campinas.

BALDIN, Nelma; MUNHOZ, Elzira. M. B..(2011), "Snowball (Bola de Neve): Uma técnica metodológica para pesquisa em Educação Ambiental Comunitária”. In: X EDUCERE e I.

BERSANI, AnaElisa.(2015),O(extra)ordinário da ajuda: histórias não contadas sobre desastre e generosidade na Grand'Anse, Haiti. Dissertação de Mestrado. Universidade Estadual de Campinas - Campinas.

CASSARINO, Jean-Pierre. (2013), “Teorizando sobre a migração de retorno: uma abordagem conceitual revisitada sobre migrantes de retorno”. In: Revista Interdisciplinar da Mobilidade Humana, Brasília, Ano XXI, n. 41, p. 21-54, jul./dez. 2013. Disponível em:<http://www.scielo.br/scielo.php?pid=S1980- 
$-85852013000200003 \&$ script $=$ sci_abstract\&tlng $=p t>$. Acesso em: 02 de março de 2020.

CAVALCANTI, Leonardo; PARELLA, Sònia. (2013), "El retorno desde una perspectiva transnacional". Revista Interdisciplinar da Mobilidade Humana, Brasília, v. 21, n. 41, p. 9-20, jul./dez. 2013. http:// dx.doi.org/10.1590/S1980-85852013000200002. Disponível em: < http://www.scielo.br/pdf/remhu/v21n41/02.pdf>. Acesso em: 29 dez. 2014.

COGO, Denise, BADET, Maria Souza. (2013), Guia das Migrações Transnacionais e Diversidade Cultural para Comunicadores: Migrantes no Brasil.1 ed. Bella terra: Instituto Humaitas Unisinos; Instituto de la Comunicación de la UAB.

DIEME, Kassoum. (2016), Imigração haitiana e política de acolhimento institucional na cidade de São Paulo: 2010-2015. Dissertação de Mestrado. Universidade Estadual de Campinas - Campinas.

. (2017), "Haiti e suas migrações".In: BERSANI, Ana Elisa e JOSEPH, Handerson (org.). Dossiê: Dinâmicas migratórias haitianas no Brasil: desafios e contribuições.Temáticas: Revista dos Pós-graduandos em Ciências Sociais. UNICAMP/ IFCH, v. 25, nº49/50.

.; MACEDO, Marília de; QUINTINO, Felipe; TONHATI, Tânia. (2019), "Autorizações concedidas pelo Conselho Nacional de Imigração - CNIg”. In: CAVALCANTI, Leonardo; OLIVEIRA, Tadeu; MACEDO, Marília (org.). Imigração e Refúgio no Brasil. Relatório Anual 2019. Série Migrações, OBMigra.

DUMONT, Gérard-François. (2019), «Les migrations internationales et l'Afrique: des logiques Sud-Nord ou Sud-Sud?». Les analyses de Population \& Avenir, pp.1-14.

DUROUX, Rose. (2011), “Imigração. França/Europa”. In: MONTANDON, Alain (dir.). O livro da Hospitalidade: acolhida do estrangeiro na história e nas culturas. Editora Senac São Paulo.

FERNANDES, Duval e CASTRO, Mariada Consolação. G. de.(2014). Projeto: Estudos sobre a migração haitiana aoBrasil e diálogo bilateral. Belo Horizonte.

GODOY, Gabriel Gualano de. (2011), "O caso dos haitianos no Brasil e a via da proteção humanitária complementar”. In: RAMOS, André de Carvalho et al. 60 anos de ACNUR, Perspectivas de futuro. São Paulo. p. 45-68.

HANDERSON, Joseph. (2015), Diaspora. As dinâmicas da mobilidade haitiana no Brasil, noSuriname e na Guiana Francesa. Tese de Doutorado.UFRJ/ Museu Nacional - Rio de Janeiro.

. (2016), "A historicidade da (e)migraçãointernacionalhaitiana. O Brasil como novoespaço migratório”. A imigração haitiana no Brasil: características sócio-demográficas e laborais na região sul e no Distrito Federal. 1ed.Santiago: OIM/Universidad de Desarrollo (UDD), 2016, v. 1, p. 85-107. 
MAMED, Letícia Helena. (2018), "Haitianos no Brasil: a experiência da etnografia multisituada para investigação de itinerários migratórios e laborais sul-sul”. In: BAENINGER, Rosana et al. (org.). Migrações Sul-Sul. Campinas, SP: Núcleo de Estudos de População "Elza Berquó” - Nepo/Unicamp, 2ªd..

MARCUS, George. (1995), "Ethnography in/of the world system: the emergence of multi-sited ethnography”. Annual Review of Anthropology. 24 (1), 95-117.

Margolis, Maxine. Goodbye Brazil: émigrés from the land of soccer and samba. Wisconsin: The University of Wisconsin Press, 2013.

NOLASCO, Carlos e RIBEIRO, Joana Sousa, (2018), "Entre Sul e Norte: singularidades das migrações na saúde e no desporto em Portugal”, e-cadernos CES [Online].

OCDE/INURED. (2017), Paysage de la migration en Haiti. In : Interactions entre politiques publiques, migrations et développement en Haiti. Disponível em: https://www.oecd-ilibrary.org/docserver/9789264278844-6-fr.pdf?expire $\mathrm{s}=1580271266 \& \mathrm{id}=\mathrm{id} \&$ accname $=$ guest\&checksum $=$ 69DE5E73DF0107A15 DE57346F1CE06B1.

OLIVEIRA, Antônio Tadeu Ribeiro. (2016), "A inserção dos estrangeiros no mercado de trabalho formal: o que nos diz a RAIS? In: CAVALCANTI, Leonardo; OLIVEIRA, Antônio Tadeu R.; ARAUJO, Dina (org.). A inserção dos imigrantes no mercado de trabalho brasileiro. Relatório Anual 2016. Observatório das Migrações Internacionais; Ministério do Trabalho/Conselho Nacional de Imigração e Coordenação Geral de Imigração. Brasília, DF: OBMigra.

OLIVEIRA, Antônio Tadeu Ribeiro. (2018), "Movimentação e registro de migrantes no Brasil: dados do STI e SINCRE”. In: CAVALCANTI, Leonardo; OLIVEIRA, Tadeu; MACEDO, Marília (org.). Migrações e mercado de trabalho no Brasil. Relatório Anual 2108. Série Migrações. Observatório das Migrações Internacionais; Ministério do Trabalho/Conselho Nacional de Imigração e Coordenação Geral de Imigração. Brasília, DF: OBMigra.

OLIVEIRA, Márcio; KULAITIS, Fernando. (2017), "Habitus imigrante e capital de mobilidade: a teoria de Pierre Bourdieu aplicada aos estudos migratórios”. Mediações - Revista de Ciências Sociais, v. 22, n 1, p. 15-47.

PATARRA, Neide Lopes. (2012), “Brasil: país de imigração?”. e-metropolis $\mathrm{n}^{\circ}$ 09, pp. 6-18.

PEREDA, Lorena del Pilar. (2019) Migración haitiana en Brasil: una aproximación a partir de las redes migratorias. Dissertação de Mestrado. Universidade de Brasília - Brasília.

SANTOS, Boaventura de Sousa. (2002), “Os processos da globalização”. In: SANTOS, Boaventura de Sousa (org.). A globalização e as ciências sociais. 2. Ed. - São Paulo. Cortez. 
SAYAD, Abdelmalek. (1998). A imigração ou os paradoxos da alteridade. São Paulo.

. (2000), O retorno - elemento constitutivo da condição do imigrante. Volume especial de Travessia - Revista do Migrante, ano XIII, número especial.

SEGUY, Franck. (2014), Catástrofe de janeiro de 2010, a "internacional comunitária” e a recolonização do Haiti. Tese de Doutorado. Universidade Estadual de Campinas - Campinas.

SEYFERTH, Giralda. (2002), "Colonização, imigração e a questão racial no Brasil”. In: Revista USP, São Paulo, nº53, março/maio. p. 117-149.

SOLÉ, Carlota., CAVALCANTI, Leonardo e PARELLA, Sona. La inmigración brasileña en la estructura socioeconómica de España. Madrid: Documentos del Observatório permanente de la inmigración de España, Gobierno de España, 2011.

TELEMAQUE,Jenny.(2012),Imigraçãohaitiananamídiabrasileira:entrefatose representações. Monografia(GraduaçãoemComunicaçãoSocial:Publicidadee Propaganda). Escola de Comunicação ECO/UFRJ.

TONHATI, Tânia; CAVALCANTI, Leonardo; OLIVEIRA, A. Tadeu. (2016),“Os Imigrantes Haitianos no Brasil: Formas de Entrada, Permanência e Registros”. In: A imigração haitiana no Brasil: características sócio-demográficas e laborais na região sul e no Distrito Federal. 1 ed. Santiago: OIM/Universidad de Desarrollo (UDD), 2016, v. 1, p. 24-40.

TONHATI, Tânia. The transnational families, migration and Brazilian family practices. 1. ed. Curitiba: CRV, 2019. v. 1. 280p.

THOMAZ, Omar Ribeiro. (2010), O terremoto no Haiti, o mundo dos brancos e o Lougawou. Disponível em: < http://www.scielo.br/pdf/nec/n86/n86a02. $\mathrm{pdf}>$.

\section{(c) (i)}

Licenciado sob uma Licença Creative Commons Attribution 3.0 